\title{
REFLEXÕES SOBRE MARIO VARGAS LLOSA E A CONSTRUÇÃO DISCURSIVA DA AMAZÔNIA PERUANA EM EL HABLADOR
}

\author{
Ximena Antonia Díaz Merino ${ }^{1}$
}

\begin{abstract}
RESUMO
A Amazônia tem uma dimensão discursiva e sua representatividade se constitui a partir das criações simbólico-literárias que por meio dos romances contribuem para a configuração imagética dessa região. Destaca-se neste estudo a narrativa etnográfica de Mario Vargas Llosa em sua obra El Hablador (1987). Nela é descrito um grupo indígena da Amazônia peruana a partir de duas visões, a do indígena e a de um jovem escritor do Peru que se encontra em Florença. Esta reflexão objetiva a análise das duas perspectivas apresentadas por Vargas Llosa com o intuito de ler a obra como enunciação sobre a Selva Amazônica peruana relacionada ao homem local, ao espaço geográfico, às tradições culturais e à natureza. El Hablador pode ser considerada uma narrativa de cunho etnográfico pois revela uma representação do indígena construída a partir dos procedimentos etnográficos de observação, recolecção e registro de dados.
\end{abstract}

Palavras-chave: Amazônia. Relato etnográfico. Mario Vargas Llosa

\begin{abstract}
Amazonia is a discursive construction and its representativeness is generated from the symbolicliterary creations through the novels that contributed to the imaginary recreation of the region. This work highlights the ethnographic narrative from Mario Vargas Llosa in his book El Hablador (1987). This Narrative describes an indigenous group from Peruvian Amazonia from two perspectives, indigenous community and from a young Peruvian writer, in Florence. This reflection aims to analyse the two optics, presented by Vargas Llosa, as an enunciation about the Peruvian Amazonian Forest assimilating it to local community, geographic area, cultural traditions and to the nature itself. $E l$ Hablador can be considered an ethnographic narrative as it reveals a representation of indigenous man clearly constructed by ethnographic observation and by data research and collection;
\end{abstract}

Key words: Amazonia; Ethnographic representation; Mario Vargas Llosa.

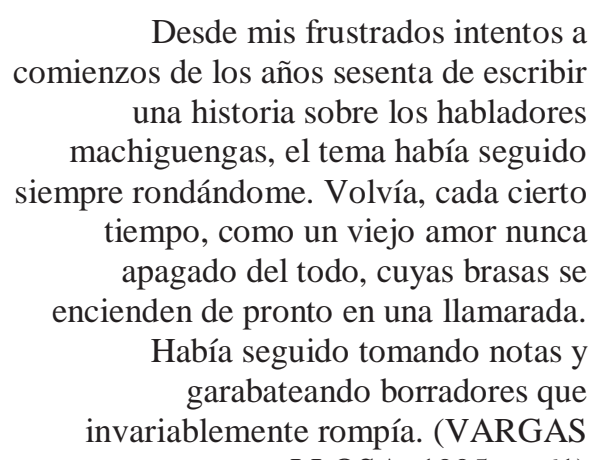

LLOSA, 1995, p. 61)

O estudo etnográfico possibilita o resgate e preservação das culturas das sociedades em processo de extinção, pois envolve diversas maneiras de pensar e de escrever desde a perspectiva da observação participativa, além de permitir a inserção do observador na cultura

\footnotetext{
${ }^{1}$ Possui Estágio Pós-doutoral em História pela Universidade do Estado do Rio de Janeiro/UERJ (2017). Doutora e Mestre em Letras Neolatinas opção Literaturas Hispânicas pela Universidade Federal do Rio de Janeiro/UFRJ. Atualmente é Professora Adjunta de Culturas e Literaturas Hispânicas do Departamento de Letras do Instituto Multidisciplinar da Universidade Federal Rural do Rio de Janeiro/UFRRJ. E-mail: ximenadm2@gmail.com
} 
objeto enquanto olha para essa cultura. A etnografia envolve um conhecimento com um duplo fim: por um lado, serve de base para as ciências humanas, por outro, garante o registro da memória das culturas ágrafas. Este segundo aspeto constitui para James Clifford uma das pedras angulares da antropologia do século XX: a construção retórica das culturas em processo de extinção. Levando em consideração que as sociedades indígenas em geral têm enfrentado o implacável progresso urbano e a unificação nacional dos territórios em que estão inseridas e que essas imposições têm resultado no aniquilamento de suas de línguas, cosmologias e valores culturais, o estudo etnográfico se apresenta como alternativa para sua preservação.

Ao longo da história, o etnógrafo preocupado em não ser confundido com o missionário, o viajante ou o funcionário do governo colonial, buscou construir em torno de si mesmo a aura de uma experiência voltada para um conhecimento que se pretende objetivo. Para isso, uma estratégia textual decisiva orientava sobre a necessidade do apagamento dos indícios que pudessem macular a pureza do encontro entre o pesquisador e os nativos: nada era dito sobre os preparativos da expedição, sobre a eventual posição de força do governo colonial propiciando a estada do etnógrafo, ou sobre as interferências decisivas dos informantes nativos. E ficava de fora, principalmente, o intenso processo subjetivo, pleno de ambivalências, vivenciado pelo etnógrafo. O caráter negociado, polifônico, do conhecimento produzido em campo dava lugar no texto a um monólogo autoral com um mínimo de fissuras.

Pressionado pelas transformações decorrentes da descolonização e da emergência dos movimentos das minorias, esse modelo começou a viver seu ocaso a partir dos anos 60 do século XX. Nesse novo cenário, marcado por um intenso translado de povos, de experiências e saberes, produziu-se uma fabulosa multiplicação de vozes, e o monólogo que caracterizou a etnografia até então, passou a soar como um anacronismo.

Apoiando-nos novamente em James Clifford, o etnógrafo é um criador que a partir de seus apontamentos constrói ficções de novos mundos com a finalidade de representar o que está observando, motivo pelo qual as figuras do etnógrafo e do novelista podem ser tidas como equiparáveis, já que os dois compõem, por meio de símbolos e de uma técnica compartilhada, o imaginário do Outro. Argumenta Clifford:

Os relatos específicos contidos nas etnografias jamais podem ser limitados a um projeto de descrição científica, na medida em que a tarefa principal do trabalho é tornar o comportamento de um modo de vida diferente humanamente compreensível [...] O que se vê num relato etnográfico coerente, a construção figurada do outro, está conectado numa dupla estrutura contínua, com a qual se entende [...] $\mathrm{O}$ comportamento estranho é retratado como significativo dentro de uma rede comum 
de símbolos - uma base comum de atividade compreensível válida para o observador, e para o observado e por implicação para todos os grupos humanos. (CLIFFORD, 2002, p. 67-68).

O crítico cubano Roberto González Echevarría defende que, a partir da segunda década do século XX, o discurso antropológico, enquanto relato científico ocidental dominante, influenciou as formas e o conteúdo da narrativa latino-americana. Para González Echevarría, o propósito da etnografia como técnica da antropologia transferiu-se para a literatura como mecanismo para criar um conhecimento da natureza, do primitivo e desse Outro desconhecido no ocidentalizado.

Em linha com o que se afirmou anteriormente, Mario Vargas Llosa, em El Hablador (1974), desafia a possibilidade antropológica científica de interpretar uma cultura, bem como a subjetividade que implica a relação do objeto estudado e o sujeito observador. Cabe destacar que nessa narrativa Vargas Llosa se utiliza das experiências adquiridas em suas viagens à Amazônia. O escritor peruano labora a figura do indígena peruano a partir das técnicas etnográficas de observação, recolecção e registro de dados. A obra se constitui num informe antropológico, num diário de campo, que procura descobrir a origem dos sistemas sociais das culturas latino-americanas primitivas e sua relação com o mundo ocidental. Da mesma maneira que na etnografia, em El Hablador encontramos dois tipos de observadores que se configuram nos narradores da cultura machiguenga: um narrador direto participante, um hablador, narrador ambulante da tribo machiguenga, e um narrador anônimo auto ficcional, um jovem escritor peruano, duas vozes que se alternam para relatar os dois lados de uma mesma história.

Por um lado, o narrador anônimo auto ficcional, que se identificaria com o próprio novelista, evoca as lembranças de um amigo de juventude que era chamado pelo apelido de Mascarita que estava fascinado pela cultura amazônica, como se ilustra no seguinte fragmento de El Hablador:

\footnotetext{
- Que esas culturas [indígenas] deben ser respetadas -dijo [Mascarita], suavemente, como si, por fin, comenzara a serenarse. Y la única manera de respetarlas es no acercarse a ellas. No tocarlas. Nuestra cultura es demasiado fuerte, demasiado agresiva. Lo que toca, lo devora. Hay que dejarlas en paz. ¿No han demostrado de sobra que tienen derecho a seguir siendo lo que son? - Eres un indigenista cuadriculado, Mascarita - le tomé el pelo - (VARGAS LLOSA, 1995, p.39).
}

Na citação Saúl Zuratas, o Mascarita, revela uma forte preocupação pela preservação da cultura indígena. O apelido Mascarita apresenta dentro da obra um duplo sentido, faz referência à mancha escura que cobria a metade de seu rosto e à dupla personalidade que oculta e que somente é revelada ao final do texto. De acordo com a narrativa, Mascarita tinha 
deixado a Faculdade de Direito para dedicar-se ao curso de Etnologia. Como consequência de suas constantes viagens à Amazônia, Saúl Zuratas diz: "Lo que se está haciendo en la Amazonía es un crimen [...] ¿Adónde se pueden seguir yendo? Los empujan de sus tierras desde hace siglos, los echan cada vez más adentro, más adentro. Lo extraordinario es que, a pesar de tantas calamidades, no hayan desaparecido. Ahi están siempre, resistiendo" (VARGAS LLOSA, 1995, p. 9).

Por outro lado, um anônimo contador de histórias, um hablador, memória viva dos indígenas machiguengas da Amazônia peruana, narra poeticamente a sua própria existência e a história e mitos de seu povo:

Después, los hombres de la tierra echaron a andar, derecho hacia el sol que caía. Antes, permanecían quietos ellos también. El sol, su ojo del cielo, estaba fijo. Desvelado, siempre abierto, mirándonos, entibiaba el mundo. Su luz, aunque fuertísima, Tasurinchi la podía resistir. No había daño, no había viento, no había lluvia. Las mujeres parían niños puros. Si Tasurinchi quería comer, hundía la mano en el río y sacaba, coleteando, un sábalo; o, disparando la flecha sin apuntar, daba unos pasos por el monte y pronto se tropezaba con una pavita, una perdiz o un trompetero flechados. Nunca faltaba qué comer. No había guerra. Los ríos desbordaban de peces y los bosques de animales. Los mashcos no existían. Los hombres de la tierra eran fuertes, sabios, serenos y unidos. Estaban quietos y sin rabia. Antes que después (VARGAS LLOSA, 1995, p.16).

Como é possível observar no excerto anterior, esse hablador concentra em sua voz a memória viva de sua comunidade e aparece como uma figura que causa grande atração nos membros da tribo, que ficam como que hipnotizados durante horas sem perceber a passagem do tempo. A figura do hablador surge na narrativa a partir da conversa entre o jovem peruano e os linguistas Schneil por ocasião da primeira viagem à selva amazônica em 1958. Os linguistas descrevem os habladores como:

[...] ese personaje raro, que no parece curandero ni sacerdote - dijo, de pronto, la señora Schneil. [...] -Tal vez, conversador. O, más bien, hablador - dijo, al fin. Y pronunció de nuevo el ruido: bronco, sibilante, larguísimo. - Sí - sonrió él -. Creo que es lo más aproximado. Hablador. Nunca habían visto a ninguno. Por su puntillosa discreción - su temor a irritarlos- nunca habían pedido a sus huéspedes una explicación detallada sobre las funciones que cumplía entre los machiguengas, ni que les precisaran si se trataba de uno o de muchos, o, incluso, aunque tendían a descartar esta hipótesis, si, en vez de seres concretos y contemporáneos, se trataba de alguien fabuloso, como Kientibakori, patrón de los demonios y creador de todo lo ponzoñoso e incomestible (VARGAS LLOSA, 1995, p.16).

No decorrer da narrativa, Mascarita vai se afastando de seu amigo até desaparecer. O jovem escritor indaga sobre o paradeiro de Saúl, mas não consegue informação. Ele dedica-se também ao estudo da tribo amazônica que tanto obcecava seu amigo, desde Florença, esse narrador auto ficcional constrói o perfil do indígena a partir de informes e testemunhos de 
outras pessoas, ou seja, desde um locus enunciativo distanciado do objeto de estudo: primeiro desde a Itália e depois a partir de uma fotografia que retrata um grupo indígena Machiguenga. Interage com científicos, antropólogos, etnólogos e linguistas que lhe proporcionam informações para seu estudo. Sobre sua primeira visita à Amazônia no ano de 1958 revela:

[...] el recuerdo más memorable y recurrente de aquel viaje sería lo que les oí contar, en Yarinacocha, a una pareja de lingüistas: los esposos Schneil. Al principio, me pareció que era la primera vez que oía nombrar a aquella tribu. Pero, de pronto, me di cuenta que era la misma sobre la que había oído tantas historias a Saúl, aquella con la que entró en contacto desde su primer viaje a Quillabamba: los machiguengas [...] Fue ella [esposa Schneil] la que me habló de la cosmogonía fluvial del machiguenga, donde la Vía Láctea era el río Meshiareni por el que bajaban los innumerables dioses y diosecillos de su panteón a la tierra y por el que subían al paraíso las almas de sus muertos. Les pregunté si tenían fotografías de las familias con las que habían vivido. Me dijeron que no. Pero me mostraron muchos objetos machiguengas (VARGAS LLOSA, 1995, p. 35).

No fragmento anterior, verifica-se que o jovem escritor precisa recorrer aos antropólogos ou aos linguistas que tinham interagido com o grupo indígena, e a partir dessas informações formula o seu discurso. Para o hablador imerso na tribo, esse participa das dinâmicas do grupo, configurando um observador participante que apresenta o modo de vida dos machiguenga a partir das informações coletadas nos diálogos estabelecidos com os membros da tribo, ou seja, de dentro, como ilustrado no seguinte fragmento da novela, um diálogo entre o hablador e um membro da tribo:

«Entonces, es verdad, te robaste a una yaminahua», le comenté a Tasurinchi. Dice que no se la robó. La cambió por una sachavaca, un saco de maíz y otro de yuca, más bien. «Los yaminahuas deberían alegrarse, eso que les di vale más que ella», me aseguró. Le preguntó a la yaminahua en mi delante: «¿No es así?» Y ella asintió: «Sí, lo es», diciendo. También eso le entendí. (VARGAS LLOSA, 1995, p.43-44).

Na citação anterior se observa que o discurso do hablador se configura após sua inserção no interior da tribo, com base na experiência humana e no simbolismo das interações sociais como mecanismo de interpretação de uma cultura; já o discurso que apresenta o narrador não participante, surge de fontes científicas. Dessa maneira, os dois tipos de observador-narrador presentes na obra revelam formas diferentes de coletar informações para construir o conhecimento do indígena. Por outras palavras, duas vozes, que da mesma forma que na etnografia, constroem o conhecimento recorrendo a modos diferentes de coleta e apresentação dos dados.

Misha Kokotovic (2001, p. 455), um comentador de Vargas Llosa, considera que o discurso ocidental do jovem jornalista é insuficiente para representar a realidade dos indígenas machiguengas e acrescenta que a figura do hablador constitui a solução para narrar 
a intimidade da tribo de uma forma mais autêntica, posto que reproduz uma cultura oral passível de ser percebida num relato que transcreve exatamente o ouvido. Do mesmo modo que o etnógrafo-participante, a narração do hablador imita, mediante a transcrição, aquilo que escuta. Portanto, os dois tipos de narrador em El hablador contrapõem o discurso científico ocidental e a oralidade como formas de representação do indígena. O observador não participante constrói um relato antropológico interpretativo, que planteia contradições epistemológicas e conflitos com as fontes de informação. O relato se aproxima ao mundo indígena interpondo o véu das disciplinas científicas, às que recorre constantemente para interpretar a cultura machiguenga, enquanto que o narrador participante dá voz ao indígena, de forma que a cultura nativa americana é narrada como uma experiência vivida que aproxima o leitor à visão de mundo do nativo.

A partir do diálogo que se estabelece entre o jovem e Mascarita, no fragmento citado a seguir, pode-se afirmar que o mundo indígena constitui para o jovem peruano um obstáculo que impede o progresso da nação:

[...] A veces, para ver hasta dónde podía llevarlo «el tema», yo lo provocaba. ¿Qué proponía, a fin de cuentas? ¿Que, para no alterar los modos de vida y las creencias de unas tribus que vivían, muchas de ellas, en la Edad de Piedra, se abstuviera el resto del Perú de explotar la Amazonía? [...] No teníamos alternativa. Si el precio del desarrollo y la industrialización, para los dieciséis millones de peruanos, era que esos pocos millares de calatos tuvieran que cortarse el pelo, lavarse los tatuajes y volverse mestizos - o, para usar la más odiada palabra del etnólogo: aculturarse -, pues, qué remedio (VARGAS LLOSA, 1995, p.10).

O narrador-externo estabelece sua posição apresentando o povo machiguenga como minoria primitiva, selvagem e atrasada, como um problema para o desenvolvimento do Peru. O crítico peruano Antonio Cornejo Polar (1996, p. 25) destaca, com relação ao imaginário indígena presente em El Hablador, que o narrador não participante [jovem escritor] diminui a maneira de viver do indígena peruano frente ao modo de vida do Peru ocidentalizado. Posição revelada na narrativa ao se fazer a descrição de uma viagem realizada por ele a um povoado machiguenga, em que se refere aos indígenas como aqueles:

[...] ancestros: los cazadores, los recolectores, los flecheros, los nómadas, los irracionales, los mágicos, los animistas. También eso era el Perú y sólo entonces tomaba yo cabal conciencia de ello: un mundo todavía sin domar, la Edad de Piedra, las culturas mágico-religiosas, la poligamia, la reducción de cabezas (en una localidad shapra, de Moronacocha, el cacique Tariri nos explicó, a través de un intérprete, la complicada técnica de relleno y conocimientos que exigía la operación), es decir, el despuntar de la historia humana (VARGAS LLOSA, 1995, p.29). 
O relato transcrito desconstrói o valor do indígena exaltado anteriormente pelo hablador por meio do mito e da oralidade, e os define como uma linha divisória que estanca os processos de uma nação. Segundo a perspectiva do narrador não participante, devido ao espírito da tribo dos indígenas amazônicos o Peru não explora a totalidade de seus recursos naturais e portanto não se integra como provedor principal de matérias primas a uma economia global e questiona: “¿Deberían dieciséis millones de peruanos renunciar a los recursos naturales de tres cuartas partes de su territorio para que los sesenta u ochenta mil indígenas amazónicos siguieran flechándose tranquilamente entre ellos, reduciendo cabezas y adorando al boa constrictor ${ }^{2}$ [...]" (VARGAS LLOSA, 1995, p.10).

Pode-se afirmar, então, que do berço da civilização ocidental, o jovem escritor propõe que o desenvolvimento e a industrialização do Peru requerem a renúncia ao componente indígena. Para o jovem peruano, o espírito da tribo, os modos de vida primitiva embasada na cosmogonia mítica irracional e na organização social não coletiva não são elementos de admiração; pelo contrário, são obstáculos que impedem alcançar a modernidade e a integração homogénea dos indivíduos a um mercado global. Mediante a desconstrução do indígena como cultura ideal, o narrador não participante sugere que a interpretação indigenista das tribos amazônicas que relata o hablador [observador-participante] é uma invenção.

A partir do questionamento do jovem escritor a Mascarita e da exposição das práticas e da estrutura social indígena, o narrador não participante enfatiza que se trata de formas de vida inferiores ao modo de vida ocidental, na medida em que os membros da tribo são seres não sociais e entidades humanas que não conformam a coletividade:

- ¿En serio o te parece que la poligamia, el animismo, la reducción de cabezas y la hechicería con cocimientos de tabaco representan una forma superior de cultura, Mascarita?[...] Estaban en movimiento desde tiempos remotos y era probable que jamás hubieran vivido de manera gregaria, en colectividades. El hecho de haber sido desplazados, cada cierto tiempo, por tribus más aguerridas, y por los blancos -en los períodos de las «fiebres»: la del caucho, la del oro, la del palo de rosa, la de la colonización agrícola- hacia regiones cada vez más insalubres y estériles, donde era imposible la supervivencia para grupos numerosos, había acentuado su fragmentación y desarrollado en ellos un individualismo casi anárquico. No existía un solo poblado machiguenga. No tenían caciques y no parecían conocer otra autoridad que la de cada padre en su propia familia (VARGAS LLOSA, 1995, p. 11, 33).

O indígena apresentado pelo jovem escritor é um ser selvagem, atrasado, violento e irracional; características que desmitificam o caráter harmônico, coletivo e edénico que o

\footnotetext{
${ }^{2}$ É uma serpente que pode chegar a um tamanho adulto de $2 \mathrm{~m}$ a $4 \mathrm{~m}$. Existe no Brasil, onde é a segunda maior cobra e pode ser encontrada em diversos locais, como na Mata Atlântica, restingas, mangues, no Cerrado, na Caatinga e na Floresta Amazônica.
} 
indigenismo lhe atribui às culturas primitivas americanas. Neste sentido, através de sua narrativa Vargas Llosa emite juízos de valor sobre a cultura indígena da Amazônia peruana e assevera que a figura do hablador é uma representação regional mediada pela paixão do amor à terra e ao primitivo; enquanto que o indígena do escritor é uma projeção atravessada pelos sistemas ocidentais de representação.

Dessa forma, pode-se afirmar que a narração científica ocidental desqualifica a narração indígena do hablador, já que esta última se constrói a partir de uma mitologia embasada em fatos sociais não verificáveis, e desde os sentimentos subjetivos do observador participante. Da mesma maneira que o discurso do jovem escritor questiona a subjetividade da aproximação regionalista indigenista que apresenta o hablador, a novela debate a subjetividade implícita na aproximação progressista ocidental do indígena.

O narrador, observador indireto, inventa uma realidade indígena mediante um sistema ocidental de significados. Ele concede vida às fotografias dos indígenas periféricos desde um discurso dominante. Por exemplo, quando o jovem descreve a silhueta de um homem numa fotografia, o faz animando uma imagem muda; lhe dá significado e contexto à fotografia a partir de suas percepções:

\footnotetext{
Vine a Firenze para olvidarme por un tiempo del Perú y de los peruanos y he aquí que el malhadado país me salió al encuentro esta mañana de la manera más inesperada [...] Al primer golpe de vista se advertía que aquella comunidad de hombres y mujeres sentados en círculo, a la manera amazónica - parecida a la oriental: las piernas en cruz, flexionadas horizontalmente, el tronco muy erguido-, y bañados por una luz que comenzaba a ceder, de crepúsculo tornándose noche, estaba hipnóticamente concentrada. Su inmovilidad era absoluta. Todas las caras se orientaban, como los radios de una circunferencia, hacia el punto central, una silueta masculina que, de pie en el corazón de la ronda de machiguengas imantados por ella, hablaba, moviendo los brazos. (VARGAS LLOSA, 1995, p. 3-4).
}

Assim, o discurso do narrador ocidental, apoiado na ciência e no uso de instrumentos que buscam reproduzir a realidade, está mediado pela subjetividade do sistema ocidental de significação. Um sistema que entende o Outro como um ser inferior que se opõe a seu caráter de sujeito observador desde um sistema de códigos inconsistentes com a realidade indígena. Justifica o carácter dominante do poder de ocidente e a posição de dependência das minorias sociais indígenas ante uma força globalizada e progressista. A novela lança mão das técnicas narrativas da etnografia como veículo de juízo ao discurso ocidental dominante da antropologia e suas escritas. A este respeito, importa lembrar o que o antropólogo Maurice Leenhardt sustentou sobre o trabalho de campo, a reciprocidade e a elaboração do texto etnográfico: "Quando um europeu vive dois ou três anos entre os selvagens, ele está 
totalmente convencido de que sabe tudo sobre eles; quando fica dez anos, ou quase, entre eles, se for um homem observador, ele vai achar que sabe muito pouco e aí ele está começando a aprender." (CODRINGTON, 1972, p. VII).

Passados mais de vinte anos da desaparição de Mascarita, o jovem escritor acredita que seu amigo se transmutou em um hablador, tornando-se no porta-voz dos direitos e das tradições dos machigengas. Cabe destacar que, após essa primeira visita à selva peruana e do primeiro encontro com os Scheneil, o jovem escritor passou a ter um grande interesse pela cultura machiguenga, em especial pela figura desse narrador oral que provavelmente ainda existia. Durante os anos que se passaram após essa viagem frequentemente se perguntava:

\begin{abstract}
¿Por qué los etnólogos modernos jamás nombraban a los habladores? Era una pregunta que me hacía cada vez que llegaba a mis manos alguno de esos estudios o trabajos de campo y descubría que tampoco esta vez se mencionaba ni siquiera de paso a aquellos ambulantes contadores de cuentos que a mí me parecían el rasgo más delicado y precioso de aquel pequeño pueblo [...] ¿Por qué había sido incapaz, en el curso de todos aquellos años, de escribir mi relato sobre los habladores? [...] ¿Cuántas veces, en estos veintitrés años, había pensado en los machiguengas? ¿Cuántas veces había tratado de adivinarlos, de escribirlos, cuántos proyectos había hecho para viajar a sus tierras? Por culpa de ellos, todos los personajes o instituciones que pudieran parecerse o de alguna manera asociarse en el mundo con el hablador machiguenga habían ejercido una instantánea fascinación sobre mí. (VARGAS LLOSA, 1995, p.16,64)
\end{abstract}

O interesse pelos habladores é revelado aos Scheneil em 1981, após vinte e três anos de sua primeira visita à região dos machiguengas:

[...] Les dije que, por una razón difícil de explicar, la existencia de esos habladores, saber lo que hacían y la función que ello tenía en la vida de su pueblo, había sido en esos veintitrés años un gran estímulo para mi propio trabajo, una fuente de inspiración y un ejemplo que me hubiera gustado emular. (VARGAS LLOSA, 1995, p.68-69)

De acordo com os Scheneil, os machiguengas não escondiam nada, contavam tudo sobre suas crenças e tradições, mas os habladores era o único tema que evitavam. Por fim, Edwin Schneil revela que em vinte e cinco anos de estada na selva teve a oportunidade de ouvir dois habladores:

La primera vez había sido de pura casualidad, hacía de eso lo menos diez años. Estaban en cuclillas en medio círculo, viejos y niños, hombres y mujeres, en torno a un hombre que peroraba, sentado y con las piernas cruzadas, encarándolos. Era un hablador [...] No, nunca había visto antes a ese hablador. Bastante viejo, a primera vista, aunque, usted sabe, aquí en la selva se envejece rápido. Viejo, entre los machiguengas, puede significar treinta años. Era un hombre bajo, fortachón, muy expresivo. Yo, usted, cualquiera que hable y hable esa cantidad de horas, quedaría ronco y extenuado. Pe- ro él, no. Hablaba y hablaba, con mucha energía. (VARGAS LLOSA, 1995, p.61, 69) 
Sobre a experiência com o segundo hablador, Edwin Schenell relatou: “-Tenía un gran lunar [...] Y unos pelos más colorados que los míos. Un tipo raro. Lo que los machiguengas llaman un serigórompi. Quiere decir un excéntrico, alguien distinto de lo normal. Por esos pelos color zanahoria le decimos el albino, el gringo, entre nosotros [...]' (VARGAS LLOSA, 1995, p.72).

Da revelação anterior surge a interrogação: qual dos narradores apresenta de forma mais fidedigna a cultura machiguenga? De acordo com as reflexões anteriores, se poderia afirmar que é o hablador. Contudo, no final da novela o jovem escritor revela que o hablador é produto da ficção, ou seja, a obra sugere que não existe uma representação real do outro. Ambas narrativas, participante e não participante, são uma ficção. Nesse sentido, a obra oferece a partir das duas aproximações etnográficas duas perspectivas do indígena, uma visão progressista e uma visão preservacionista; as quais são desconstruídas para sugerir que todo método de representação, sem importar a distância que afasta o observador do objeto, está mediado por subjetividades que condenam a ideia do "Outro" a ser uma ficção. Seria um simulacro de uma representação etnográfica dos machiguengas.

A personagem de Saúl Zuratas, o Mascarita, é o símbolo da ficção do científico ocidental nas representações do indígena. As perspectivas indigenistas e progressistas ocidentais do nativo americano são invenções, como no caso do jovem escritor que constrói o Outro, o hablador machiguenga, desde seu próprio sistema de conhecimento. Vargas Llosa apresenta um forte argumento a favor da assimilação, aculturação, e desaparição das culturas indígenas. Kokotovic sugere que a estrutura dos relatos na novela, desde dois observadores etnográficos ocidentais, privilegia a posição do narrador escritor, pois para entender o hablador são necessárias as informações proporcionadas pelo observador não participante. Nesse sentido, a novela parece sugerir que, se a representação do indígena é uma invenção desde qualquer um de seus enfoques, existe uma estrutura de poder que subordina o mundo machiguenga à voz do narrador ocidental. Tal como ocorre na narrativa novelística e nos cadernos etnográficos, a voz do hablador machiguenga não é mais que um reflexo construído pelo escritor. Uma interpretação subjetiva, dentro dos agitados intentos por obter objetividade, por apropriar-se e representar esse Outro concebido como marginal dentro da cultura ocidental.

Para concluir citam-se as palavras do antropólogo e etnógrafo francês Pìerre Clastres (2011, p. 64): “[...] De fato, comparado à vigorosa abundância do que é a vida de uma sociedade primitiva, o discurso do cientista parece antes o tartamudeio hesitante de um gago e vesgo ainda por cima. Portanto, um livro um pouco amargo por nos deixar na certeza de que 
nos deslocamos na superfície das significações, que deslizam um pouco mais adiante a cada passo dado para aproximar-se delas. Mas aí já não se trata de etnologia. Sendo as coisas o que elas são, a linguagem da ciência parece permanecer - por destino, talvez - discurso sobre os selvagens e não dos selvagens. Como eles, não podemos conquistar a liberdade de ser ao mesmo tempo um e outro, de estar simultaneamente aqui e lá, sem perder tudo e não ter mais lugar onde ficar. A cada um se recusa assim a astúcia de um saber que, ao tornar-se absoluto, se aboliria no silêncio. Vargas Llosa questiona em sua novela a impossibilidade de interpretar uma cultura, consciente dessa dificuldade demonstra que ancorados na ciência só se consegue construir, nas palavras de Clastres citadas acima, um "discurso sobre os selvagens e não dos selvagens". Vargas Llosa conhece o poder da palavra e o poder da voz e isso se constata em sua obsessão pelo hablador, pelo qual mantém um interesse constante. Dessa forma, o discurso do narrador ocidental, embasado na ciência e no uso de instrumentos que buscam reproduzir a realidade, está mediado pela subjetividade do sistema ocidental de significação. Um sistema que, como se indicou já, entende o indígena como um objeto inferior que se opõe ao seu caráter de sujeito observador, desde um sistema de códigos inconsistentes com a realidade indígena.

\section{REFERÊNCIAS}

CLASTRES, Pierre. Arqueologia da violência-pesquisas de antropologia política. Trad. Paulo Neves. São Paulo: Cosac Naify, 2011.

CLIFFORD, James, George E. Marcus y José L. Moreno-Ruiz. Retóricas de la antropología. Madrid: Júcar, 1991.

CLIFFORD, James. A experiência etnográfica: antropologia e literatura no século $\mathbf{X X}$. Organizado por José Reginaldo Santos Gonçalves. 2a ed. Rio de Janeiro: Ed. UFRJ, 2002.

CODRINGTON, R. H. (1891). The Melanesians. New York: Dover, 1972.

CORNEJO POLAR, Antonio. Una heterogeneidad no dialéctica: sujeto y discurso migrantes en el Perú moderno. Revista Iberoamericana. 62,1996.

GONZÁLEZ ECHEVARRÍA, R. Mito y archivo: una teoría de la narrativa latinoamericana. México: Fondo de Cultura Económica, 2000.

KOKOTOVIC, Misha. Artículos - Mario Vargas Llosa Writes Of(f) the Native: Modernity and Cultural Heterogeneity in Peru. Revista Canadiense de Estudios Hispánicos. MA25.3, 2001.

VARGAS LLOSA, Mario. El Hablador. 4ª ed. Barcelona: Editorial Seix Barral, 1995. 